\title{
Knowledge, Attitude and Practice of Mothers toward Children's Vaccination at Alfatih One in Sudan
}

\author{
Manal Bilal Mohammed1, Ahlam Al-Zahrani2 \\ ${ }^{1}$ Medical Nursing Department, General Administration and Training Development in Omdurman Islamic University, \\ Omdurman, Sudan \\ ${ }^{2}$ Maternatiy and Women Health, Nursing Faculty, King Abdulaziz University, Jeddah, Saudi Arabia \\ Email: manalbelal52@gmail.com, aealzahrani@kau.edu.sa
}

How to cite this paper: Mohammed, M.B. and Al-Zahrani, A. (2021) Knowledge, Attitude and Practice of Mothers toward Children's Vaccination at Alfatih One in Sudan. Open Journal of Nursing, 11, 557-565. https://doi.org/10.4236/ojn.2021.117047

Received: April 21, 2021

Accepted: July 12, 2021

Published: July 15, 2021

Copyright $\odot 2021$ by author(s) and Scientific Research Publishing Inc. This work is licensed under the Creative Commons Attribution International License (CC BY 4.0).

http://creativecommons.org/licenses/by/4.0/

\section{(c) (i) Open Access}

\begin{abstract}
The aim of this study was to assess knowledge, attitudes and practice of mothers towards children's vaccination. Background: Vaccine preventable diseases (VPD) are considered one of the main causes of sicknesses and deaths among children all over the world. Parents' knowledge and attitude towards immunization are likely to influence uptake. Vaccination is one of the most cost-effective public health tools to prevent infectious diseases. This study assessed knowledge, attitudes and practice of mothers towards children's vaccination. Design: Cross-sectional study was conducted from April 1st to May 1st in 2016 among mothers whose children under five years which was carried out at their home in Alfatih one. The sampling method used was simple random sampling. The first house was selected randomly according to availability of household list. Total number of mothers under study were 210 selected randomly from 400 mothers' home. Structured interviewing sheets were used to assess sociodemographic data, knowledge, attitude and practice of mothers toward vaccination. The data were analyzed using SPSS (Stand for statistical product and service solutions) version 20 . Results: It's revealed that the correlation between knowledge and practice of the studied mothers was statistically insignificant. Conclusion: More than two third of studied mothers had poor knowledge, while on other hand their practice was good towards vaccination.
\end{abstract}

\section{Keywords}

Attitude, Vaccination, Knowledge, Mothers, Practice

\section{Introduction and Background}

Immunization is the process whereby a person is made immune or resistant to 
an infectious disease, typically by the administration of a vaccine. These vaccines help to stimulate the body's own immune system to protect the person against subsequent infection or disease, therefore it depicts the ability to develop immunity [1]. Immunization is one of the most successful and cost-effective public health interventions in the constant effort of human beings against diseases that affect our wellbeing. Immunization has prevented more deaths in the past years than any other health intervention globally [2]. Kapoor and Vyas had stated that although immunization is one of the most effective, safest and efficient Public Health Interventions, and that its impact on childhood morbidity and mortality has been great its full potential was yet to be reached [3]. The Childhood immunization almost guarantees protection from many major diseases. It prevents millions of deaths per year worldwide and is widely considered to be "overwhelmingly good" by the scientific community [4]. However, 2.5 million deaths a year continue to be caused by vaccine preventable diseases, mainly in Africa and Asia among children less than 5 years old [4]. Therefore, an urgent need to find ways to increase vaccination coverage and particularly to encourage parents to have their children vaccinated [5]. Although global vaccination coverage is holding steady but estimated 22 million infants worldwide are still missing out on basic vaccines [1]. World Health Organization reported that 115 million infants worldwide received Diphtheria-Tetanus and Pertussis vaccine. In addition, there is about $85 \%$ of the world's children received one dose of measles vaccine, and received polio vaccine however, remain the polioendemic in two countries (Afghanistan \& Pakistan) [6]. In Sudan, WHO and UNICEF estimate national immunization coverage about $99 \%$ and it represents a very high percent since 2005 [7]. On the other hand, immunization prevents an estimated two to three million deaths each year from Diphtheria, Tetanus, Pertussis (whooping cough), and Measles [8]. This study aimed to assess knowledge, attitude and practice of mothers toward children's vaccination under five years, and to assess the relation between demographic data and knowledge, attitudes and practice.

\section{Material and Methods}

Cross-sectional study was conducted from April 1st to May 1st in 2016 among mother whose children under five years which was carried out at their home in ALFATIH ONE. The first house visited and selected randomly according to availability of household list. Total number of mothers sample was 210 selected randomly from 400 mothers' home. Interviews were done for participating mothers in the study and respect the refusal for some mothers. The interview questionnaires consist of demographic characteristics of mothers and children. The questionnaire includes age, education level, occupation, number of children under five years, sex of children. Knowledge was tested with 18 questions which required true or false answers relating to important of vaccination, diseases controlled by vaccination, contraindication, immunization types, the routes of vaccine administration. Every Correct answer scored $=(1)$, while an incorrect 
an-swer scored $=(0)$. The respondents were divided into fair, poor and good groups evaluated as follows: poor less than $50 \%$ while fair $=50 \%-65 \%$ and Good $=$ more than $65 \%$. Attitude likert scale of vaccination consists of 15 statements with 3 point scale (agree), (uncertain) and (disagree). The main categories of the attitude scale include importance of vaccination for children and its safety, side effects of vaccination and it must give according to schedule its effectiveness in prevention of communicable disease. Every mother was instructed to choose one of the three possible responses for each statement. Scoring system: scoring was as; agree $=2$, uncertain $=1$ and disagree $=0$ for the positive attitudes $(10$ statements), while agree $=0$, uncertain $=1$ and disagree $=2$ for the negative attitudes ( 5 statements). The total score of attitude ranged from 0 - 32. The attitude score was evaluated as; Poor $=$ less than 50\%, Fair $=50 \%-65 \%$ and Good $=$ more than 65\%. Practice tool composed of 14 questions. One mark was awarded for each correct answer, the total score of the practice ranged from 0 to 14 . The practice score was evaluated as follows; Poor $=$ less than $50 \%$, Fair $=$ $50 \%-65 \%$ score and Good $=$ more than $65 \%$ Attitude likert scale of children's vaccination.

Statistical analysis: SPSS software package (Stand for statistical product and service solutions version 20) was used for data analysis. Descriptive statistics including frequency, distribution, mean, and standard deviation were used to describe different characteristics. Chi-Square test was used to test the significance of the results. Pearson correlation was conducted to show correlations between knowledge, attitude and practice scores among the studied mothers. P-value of less than 0.05 was considered as denoting statistical significance.

\section{Results}

Table 1 represents that the studied mothers aged less than 20 (30) to less than 30 (3), 30 - 40 years (103) and more than 40 (74) with percent $14.3 \%, 1.4 \%, 49.0 \%$, $35.2 \%$ respectively Concerning mothers, occupation the same table revealed that $138(65.7 \%)$ of the studied mothers were housewives and minor of them 10 (4.8\%) were nurses, $143(68.1 \%)$ of them married and 59 (28.1\%) divorced, and 8 (3.8\%) widowed regarding to their level of education, the table shows that 80 (38.1\%) of the studied mothers were illiterate while 20 (9.5\%) same percent show their education level was primary and secondary although $60(28.6 \%)$ have a higher education.

Table 2 shows that $87(41.4 \%)$ of the studied mothers had poor knowledge score while 78 (37.1\%) had good knowledge score, and 45 (21.4\%) their knowledge were fair.

Table 3 shows that $110(52.3 \%)$ of the studied mothers had good attitudes score while $100(47.6 \%)$ had poor attitudes score, their attitudes score range between good and poor, no fair score.

Table 4 shows that $22(10.5 \%)$ of the studied mothers had poor practice score while $188(89.5 \%)$ had good practice score, their practice score range between 
Table 1. Demographic data $(\mathrm{n}=210)$.

\begin{tabular}{ccc}
\hline Variable & Frequency & $\%$ \\
Age & 30 & 14.5 \\
Less than 20 years & 3 & 1.4 \\
$20-29$ & 103 & 49.1 \\
$30-40$ & 74 & 35.2 \\
Above 40 & & \\
Occupation & 135 & 65.7 \\
house wife & 12 & 5.7 \\
Teacher & 10 & 4.8 \\
Nurse & 50 & 23.8 \\
Employer & & \\
Education & 80 & 38.1 \\
Illiterate & 20 & 9.5 \\
Primary & 30 & 14.3 \\
Intermediate & 20 & 9.5 \\
Secondary & 60 & 28.6 \\
higher education & & \\
Marital status & 143 & 68.1 \\
Married & 59 & 28.1 \\
Divorced & 8 & 38.1 \\
Widowed & &
\end{tabular}

Table 2. Distribution of the studied mothers according to their general knowledge about vaccination and knowledge scores of the study participants $(n=210)$.

\begin{tabular}{lcc}
\hline \multicolumn{1}{c}{ Characteristics } & $\mathrm{N}$ & $\%$ \\
\hline Importance of vaccination can Prevent infectious diseases & 153 & 72.9 \\
Maintain Child health & 49 & 23.3 \\
Reduce child mortality rate & 139 & 66.2 \\
Protect children from complication & 166 & 79.0 \\
Diseases controlled by obligatory vaccination Measles & 137 & 65.2 \\
Tuberculosis & 153 & 72.9 \\
Poliomyelitis & 178 & 84.8 \\
Diphtheria, Tetanus and Pertussis diseases & 137 & 65.2 \\
Hepatitis B virus & 14 & 25.2 \\
Contraindication & & \\
Malnutrition & 137 & 65.2 \\
Diarrhea & 53 & 25.2 \\
Minimal Infection & 158 & 75.2 \\
Immunological diseases & 44 & 21.0 \\
The routes of vaccine administration & & \\
Polio & & \\
BCG (Bacillus-Calmette-Guerin) & 188 & \\
DPT (Diphtheria, Tetanus and Pertussis) & 160 & \\
HBV (Hepatitis B) & 21 & \\
MMR (Measles, Mumps and Rubella) & 65 & \\
Knowledge score & 52 & \\
Poor (<50\%) & & \\
Faire (50\% - 65\%) & 87.4 \\
Good (>65\%) & 78 & \\
& & \\
\hline
\end{tabular}


Table 3. Distribution of the studied mothers according to their attitudes about vaccination and attitudes scores of the study participants $(n=210)$.

\begin{tabular}{|c|c|c|c|c|c|c|}
\hline \multirow{2}{*}{ Characteristics } & \multicolumn{2}{|c|}{ agree } & \multicolumn{2}{|c|}{ Uncertain } & \multicolumn{2}{|c|}{ disagree } \\
\hline & $\mathbf{N}$ & $\%$ & $\mathbf{N}$ & $\%$ & $\mathbf{N}$ & $\%$ \\
\hline $\begin{array}{l}\text { Positive attitude } \\
\text { Vaccination is important }\end{array}$ & 122 & 58.1 & 66 & 31.1 & 22 & 10.4 \\
\hline Vaccination is safe & 111 & 52.9 & 62 & 29.5 & 37 & 17.6 \\
\hline vaccination maintain child health & 111 & 52.9 & 62 & 29.5 & 37 & 17.6 \\
\hline vaccination is the best for each infant & 111 & 52.9 & 62 & 29.5 & 37 & 17.6 \\
\hline $\begin{array}{l}\text { recommend others to vaccinate their } \\
\text { children }\end{array}$ & 111 & 52.9 & 62 & $29 / 5$ & 37 & 17.6 \\
\hline $\begin{array}{l}\text { Vaccination must give according to } \\
\text { schedule }\end{array}$ & 111 & 52.9 & 62 & $29 / 5$ & 37 & 17.6 \\
\hline Vaccination save the community & 117 & 55.7 & 90 & 42.5 & 3 & 1.4 \\
\hline $\begin{array}{l}\text { Effective in prevention of infectious } \\
\text { diseases }\end{array}$ & 189 & 90.9 & 17 & 6.1 & 4 & 1.9 \\
\hline Vaccination reduce mortality rate & 117 & 57.1 & 90 & 42.5 & 3 & 1.4 \\
\hline $\begin{array}{l}\text { Tetanus vaccine important for infant } \\
\text { and mothers health }\end{array}$ & 117 & 57.1 & 90 & 42.5 & 3 & 1.4 \\
\hline $\begin{array}{l}\text { Negative attitude } \\
\text { Vaccines have severe side effects }\end{array}$ & 142 & 67.6 & 68 & 32.4 & 0 & 0 \\
\hline $\begin{array}{l}\text { Infant Infected with the disease which } \\
\text { immunized against }\end{array}$ & 132 & 62.3 & 68 & 32.4 & 10 & 4.8 \\
\hline Side effects cause death & 142 & 67.6 & 68 & 32.4 & 70 & 33.3 \\
\hline Vaccination important for boy than girls & 72 & 34.3 & 68 & 32.4 & 10 & 4.8 \\
\hline vaccination is harmful & 210 & 100 & 0 & 0 & 0 & 0 \\
\hline attitudes score & & $\mathrm{N}$ & & & $\%$ & \\
\hline Poor $(<50 \%)$ & & 100 & & & 47.6 & \\
\hline Faire $(50 \%-65 \%)$ & & 0 & & & 0 & \\
\hline Good (>65\%) & & 110 & & & 52.3 & \\
\hline
\end{tabular}

good and poor, no fair score. Table 5 shows the associations between mothers, knowledge score and demographic data which reveals that $33(73.3 \%)$ of educated mothers with higher education and $8(17.7 \%)$ mothers with intermediate education had a good knowledge at $\mathrm{p}<0.00001$. Table 6 shows that there were positive statistically significant correlations between mothers age and knowledge but it was a negative between age, attitude.

\section{Discussion}

Immunization is an important public health interventions strategy to reduce the morbidity and mortality associated with infectious diseases. Immunization has saved the lives of more children than any other medical intervention in the last 50 years. Vaccines are safe, simple and one of the most cost-effective ways to 
Table 4. Distribution of the studied mothers according to their practice about vaccination and practice scores of the study participants $(n=210)$.

\begin{tabular}{|c|c|c|c|c|}
\hline \multirow{2}{*}{ Characteristics } & \multicolumn{2}{|c|}{ Yes } & \multicolumn{2}{|c|}{ no } \\
\hline & $\mathbf{N}$ & $\%$ & $\mathbf{N}$ & $\%$ \\
\hline $\begin{array}{l}\text { Your infant received vaccines according to } \\
\text { Ministry of health schedule }\end{array}$ & 90 & 42.9 & 120 & 57.1 \\
\hline Reported vaccinations side effects & 51 & 24.3 & 159 & 757 \\
\hline High temperature & 22 & 10.5 & 188 & 89.5 \\
\hline Rash & 22 & 10.5 & 188 & 89.5 \\
\hline Diarrhea & 22 & 10.5 & 188 & 89.5 \\
\hline Pain & 22 & 10.5 & 188 & 89.5 \\
\hline Received anti-pyretic at vaccination day only & 51 & 24.3 & 159 & 757 \\
\hline Received anti-pyretic after vaccination & 51 & 24.3 & 159 & 757 \\
\hline Swelling of the infant feet & 22 & 10.5 & 188 & 89.5 \\
\hline Management of swelling Cold compress & 22 & 10.5 & 188 & 89.5 \\
\hline Starch & 51 & 24.3 & 159 & 757 \\
\hline Analgesic and local anti inflammatory & 22 & 10.5 & 188 & 89.5 \\
\hline Report doctor & 22 & 10.5 & 188 & 89.5 \\
\hline Practice score & & & & \\
\hline Poor $(<50 \%)$ & & & & \\
\hline Fair $(50 \%-65 \%)$ & & & & \\
\hline Good (>65\%) & & & & \\
\hline
\end{tabular}

Table 5. Associations between mothers, knowledge score and demographic data no (210).

\begin{tabular}{|c|c|c|c|c|c|c|c|c|}
\hline \multirow{3}{*}{ Socio-demographic data } & \multicolumn{6}{|c|}{ Knowledge } & \multirow[t]{3}{*}{$\mathrm{X}^{2}$} & \multirow[t]{3}{*}{$\mathbf{P}$} \\
\hline & \multicolumn{2}{|c|}{$\begin{array}{c}\text { Poor } \\
(n=87)\end{array}$} & \multicolumn{2}{|c|}{$\begin{array}{c}\text { Fair } \\
(n=45)\end{array}$} & \multicolumn{2}{|c|}{$\begin{array}{c}\text { Good } \\
(n=78)\end{array}$} & & \\
\hline & No & $\%$ & No & $\%$ & No & $\%$ & & \\
\hline \multicolumn{9}{|l|}{ Occupation } \\
\hline Employed & 12 & 13.8 & 30 & 55.6 & 60 & 77 & 78.826 & $0.00001^{*}$ \\
\hline Not employed & 60 & 69 & 15 & 34.9 & 18 & 23 & & \\
\hline \multicolumn{9}{|l|}{ Education } \\
\hline Illiterate & 24 & 27.5 & 21 & 47 & 28 & 35.9 & 24.375 & $0.00001^{\star}$ \\
\hline Primary & 21 & 24.1 & 2 & 4.4 & 3 & 6.6 & & \\
\hline Intermediate & 12 & 13.7 & 2 & 4.4 & 8 & 17.7 & & \\
\hline Secondary & 2 & 2.2 & 10 & 22.2 & 6 & 13.3 & & \\
\hline higher education & 22 & 25.2 & 10 & 22.2 & 33 & 73.3 & & \\
\hline
\end{tabular}

$\mathrm{X}^{2}$ : Chi square test. Statistically significant at: ${ }^{*} \mathrm{p} \leq 0.00001$. 
Table 6. Correlation between mothers' age, knowledge, and attitude and practice score.

\begin{tabular}{ccc}
\hline & \multicolumn{2}{c}{ Mothers, age } \\
\cline { 2 - 3 } Items & Rs & P-value \\
\hline Knowledge & 0.052 & 0.022 \\
Attitude & -043 & 0.030 \\
Practice & 0.045 & 0.136 \\
\hline
\end{tabular}

Rs: Pearson coefficient. Statistically significant at $\mathrm{p} \leq 0.05$.

save and improve the lives of children worldwide [8]. Each year, two to three million lives are saved through immunization. However, more than 22 million children still go without basic immunization that leaving them susceptible to life threatening illness and permanent disability. Immunizing children against vaccine-preventable diseases is an important factor in saving lives, increasing productivity, and alleviating poverty [9]. The present study has tried to identify the Knowledge Attitude and Practice of mothers about vaccination of their children in Alfatih one in Sudan. In this study, results reveal that near to half of the studied mothers had poor knowledge Score 87 (41.4\%) related to children, vaccination and 110 (52.3\%), more than half of mothers had good attitude score and two third 188 (89.5\%) reveal good practice towards vaccination. The results of the current study which reflect poor knowledge of mothers may be due to the low level of awareness about important of vaccination in spite of most of them were educated, lack of educational program in rural areas (Alfatih one), and their positive attitude toward vaccination may be due to the mandatory vaccination require for school registration. These findings were in agreement with; study done at Mawatch Goth, Kemari town Karachi [10], which revealed inadequate knowledge, strong positive attitude and practice of mothers. The results of this study came at contrast with knowledge score of study done in a Rural Area of North Kashmir India to assess mothers' knowledge, attitude and practice about immunization of children which showed good knowledge, good practice and good attitude of the studied mothers [11]. The same study was done in a traditional city in the United Arab Emirates which came in contrast with this study [12]. Other study done in Kosofe local Government area of Lagos state, Nigeria [13] reported that good knowledge, positive attitude and good practice of mothers towards childhood immunizations, However, Iraqi study results about parents' knowledge and practice regarding immunization related to pediatrics' immunization compliance revealed two third of parents' have adequate knowledge-practice scores which wasn't in the same line with this study [14]. Another study done in southwest Nigeria to assess knowledge and perceptions of adult males towards childhood immunizations revealed good knowledge and good perceptions [15]. Regarding association between education and knowledge score, in this study there is a significant relation between knowledge score and their level of education. It was statistically significant, $p=0.00001$, this finding was in agreement with the study done in Taif region, Saudi Arabia which studied 
knowledge and attitudes on childhood vaccination, a survey among Saudi parents $p=-0.00001[16]$. And also the study done in southwest Nigeria which founded statistically significant association between respondents' level of education and their willingness to support childhood immunization [15]. However came in contrast a study done in at Damietta Governorate which found good significant relation with knowledge score and the intermediate education level of mothers [17]. Lack of education, can lead to reduced ability to find, understand and use health information. Thus education is an important determinant of health status in developing world; well educated mothers had better health knowledge than the poorly educated. Furthermore, education may change mothers' knowledge and perception of the importance of modern medicine in the care of their children. Regarding correlations between mothers' age and knowledge, practice score in the current study the difference between mother's knowledge, attitude and age was significant. These findings are in the same line with the results done at Damietta Governorate which found a significant relation between knowledge and mother age [17]. Other study in peri-urban Karachi to assess mothers' knowledge about EPI and its relation with age-appropriate vaccination of infants which revealed a statistically significant association with age appropriate vaccine coverage which agreed with this study [18]. This correlation between age and knowledge could be justified as the knowledge level differs from younger than older, young mothers may be are interested in reading books than older mothers. Conclusion \& recommendations are depended on the findings of the present study, it could be concluded that comparing to their attitudes which represent nearly half of mothers had poor knowledge more than two third, on the other hand, their practice was good towards vaccination. There were positive statistically significant correlations between mother's age and practice and the correlation between mothers, attitude and age was a negative one. Recommendation of Health education program about vaccination for mothers are needed especially for those in rural areas through TV or radio or any mass media. Encourage meetings between mothers with children in the same age to exchange information at maternal and child. Provide mothers with vaccination booklets will explain all information about vaccination.

\section{Conflicts of Interest}

The authors declare no conflicts of interest regarding the publication of this paper.

\section{References}

[1] World Health Organization (2013) Immunization. https://www.who.int/topics/immunization/en

[2] Awosika, D. (2012) Access to Immunization and Other Public Health Interventions through the Pharmacists. West African Journal of Pharmacy, 23, 3-11.

[3] Kapoor, R. and Vyas, S. (2010) Awareness and Knowledge of Mothers of under Five Children Regarding Immunization in Ahmedabad. Healthline, 1, 12-15.

[4] GIVS (2005) Global Immunization: Vision and Strategy. WHO/UNICEF, Geneva. 
[5] Bofarraj, M.A.M. (2011) Knowledge, Attitude and Practices of Mothers Regarding Immunization of Infants and Preschool Children at AlBeida City, Libya 2008. The Egyptian Journal of Pediatric Allergy and Immunology, 9, 29-34.

[6] World Immunization Week 2016: Close the Immunization Gap.

[7] WHO (2017) UNICEF, Estimation of National Immunization Coverage.

[8] Mereena and Sujath, R. (2014) Study on Knowledge and Attitude Regarding Vaccines among Mothers of Under-Five Children Attending Pediatric OPD in a Selected Hospital at Mangalore. Journal of Nursing and Health Science, 3, 39-46. https://doi.org/10.9790/1959-03533946

[9] Paudyal, S. (2013) Knowledge, Attitude and Practice of Immunization Behaviour among Mothers Visiting Amda Hospital, Jhapa Bhairahawa Multiple Campus, Faculty of Education, Tribhuvan University.

[10] Nisar, N., Mirza, M. and Qadri, M.H. (2010) Knowledge, Attitude and Practices of Mothers Regarding Immunization of One Year Old Child at Mawatch Goth, Kemari Town, Karachi. Pakistan Journal of Medical Sciences, 26, 183-186.

[11] Hamid, S., Arshad, S., Fazli, A. and Jabeen, R. (2012) Immunization of Children in a Rural Area of North Kashmir, India: A KAP Study. Journal of Health and Allied Sciences, 11, 10.

[12] Bernsen, et al. (2011) Knowledge, Attitude and Practice towards Immunizations among Mothers in a Traditional City in the United Arab Emirates. Journal of Medical Sciences, 4, 114-121. https://doi.org/10.2174/1996327001104030114

[13] Abidoye, A.O. and Odeyemi, K.A. (2013) Knowledge, Attitude and Practice of Mothers to Childhood Immunization in Kosofe Local Government Area of Lagos State, Nigeria. International Journal of Basic, Applied and Innovative Research, 2, 66-72.

[14] Qutaiba, B., et al. (2014) Are Parents' Knowledge and Practice Regarding Immunization Related to Pediatrics Immunization Compliance? A Mixed Method Study. BMC Pediatrics, 14, 20. https://doi.org/10.1186/1471-2431-14-20

[15] Agboola, M.S., Busari, A.O., Titilola, B., Olajide, J.T., Shabi, M.O., et al. (2015) Knowledge, Attitude, Perceptions of Adult Males towards Childhood Immunizations in Southwest Nigeria. American Journal of Health Research, 3, 8-12. http://www.sciencepublishinggroup.com/j/ajhr https://doi.org/10.11648/j.ajhr.20150301.12

[16] Elbur, et al. (2014) Knowledge and Attitudes on Childhood Vaccination a Survey among Saudi Parents in Taif Region, Saudi Arabia. International Journal of Pharmacy Practice \& Drug Research, 4, 92-97.

[17] Ramadan, H.A., Soliman, S.M. and Elkader, R.G.A. (2016) Knowledge, Attitude and Practice of Mothers toward Children's Obligatory Vaccination. IOSR Journal of Nursing and Health Science, 5, 22-28. https://doi.org/10.9790/1959-0504022228

[18] Siddiqi, N., Siddiqi, A.E., Nisar, N. and Khan, A. (2010) Mothers' Knowledge about EPI and Its Relation with Age-Appropriate Vaccination of Infants in Peri-Urban Karachi. Journal of Pakistan Medical Association, 60, 940-944. 